\title{
Article:
}

\section{Service Users Facing Household Challenges}

Their experiences with task-centred coping approach

by

Rita Elisabeth Eriksen

Associate Professor, PhD

Diakonhjemmet University College

Email: r.eriksen@diakonhjemmet.no

\section{Keywords:}

Housing competence, systematic household guidance, Task Centred Coping Approach (TCCA), user participation, addiction and/or mental challenges. 


\begin{abstract}
This article is based on a study of an educational and developmental programme, in which the task-centred coping approach (TCCA) was a central part. Twenty social worker practitioners from Norwegian municipal social services (MSS) participated in the programme, and practiced TCCA with 74 of their service users. The aim of the study was to develop knowledge about how service users evolve their housing competence by utilizing TCCA.
\end{abstract}

The study was based on a way of participatory action research, in which the researcher was positioned as a partly participating researcher. The researcher tried to attain knowledge from the individualized activities of the service users and the practitioners, and use this knowledge as a contribution to developing their practice and the programme. User participation was one of the cornerstones of the study, and individualization meant matching the approaches of the practitioners to the experienced needs of the individual service user.

The target group of service users was struggling with household tasks, addiction and/or mental health problems, economy and unemployment. After TCCA, they filled out forms of retrospective self-evaluation. Analytical questions to the text led to analytical categories and condensed narratives as illustrations of their messages. The forms were collected by the practitioners without the influence of the researcher, and the informants' assessments emerge from the evaluations. However, the researcher has chosen quotations from the forms, and consecutively made her evaluations of them.

The study showed that the informants were very heterogeneous. Persistent planning, which took ongoing variations in everyday life into account, seemed to be important. In good periods, motivation for planned change was high. In vulnerable periods characterized by challenging stress, the focus had to be concentrated on social support and keeping up achieved goals. Expectations of new coping-oriented changes seemed to be less appropriate. 


\section{Background and purpose}

This article focuses on the perspectives of service users from Norwegian municipal social services (MSS) and their experiences of systematic household guidance by practicing the Task-Centred Coping Approach (TCCA). How to strengthen the housing competence of service users? The scope of homelessness is increasing. The ongoing deindustrialization, urbanization and deinstitutionalization of the last decades are some of the several accelerating factors (Sahlin, 1996). Members of the homeless group often have a history of addiction and/or mental challenges (Sullivan, Burnam, \& Koegel, 2000), as some consciously use both drugs and alcohol to cope with illness or to reduce the side effects of medication (Pettersen et al., 2013). Housing is crucial to social, physical and mental well-being, though the policy and efforts of local authorities to supply housing and target the needs of support for this group vary (Bengtsson, Jørgensen, \& Grønfeldt, 2013). Moreover, the knowledge about systematic household guidance is scarce.

In Western countries, the MSS are responsible for providing housing to people living in sub-standard conditions. The MSS strive to offer services to strengthen the housing competence of service users, and several of those who are dependent on municipal allowances feel inferior and disempowered. There is a growing interest in how this influences their welfare and ability to participate and cope as service users, as well as citizens (Underlid, 2005). The social worker practitioners do not keep themselves informed of the perspectives of the users, and their services are not coordinated. In addition, resources are insufficiently utilized (The National Board of Health Supervision, 2008). From one perspective, users face challenges such as low income, unemployment, household tasks, poor health and addiction problems. From another perspective, they have personal resources (social skills, housing competence, self-knowledge) and environmental resources (social support from persons in their informal and formal social network) (Eriksen, 2007). However, these service users are often described as a marginalized group in living condition research. This tends to have a negative influence on practitioners' understanding of the resources that the service users have, in addition to the self-perception the users have of themselves. They often have low self-esteem (Underlid, 2005). 
Rehabilitation of service users who have their own housing is relatively good. When they have a home of their own, users are in a better position to actively engage themselves in user participation and to cooperate in strengthening their housing competence (Tsemberis, 2010). TCCA is an approach that the MSS can use in service provision to the service users. This article builds upon practice-based knowledge from a way of participatory action research project with users who wanted to improve their housing competence in collaboration with social workers (Eriksen, 2011a).

From 2009-2001, social worker practitioners attended an educational and developmental programme in systematic social work (TCCA) with service users who face housing challenges. These practitioners were all employed in the MSS, dealing with both housing competence and everyday life challenges. In total, there were six gatherings (one gathering consisted of three working days), and lecturers were external and internal professionals, including the researcher of this study. The social workers delivered homework and made presentations at the gatherings. The production of knowledge was enhanced by discussing questions and experienced learning presented by various participants - service users as well as practitioners. Between the gatherings, the social workers practiced TCCA together with their service users. The practitioners took part in supervised group work with authorized, external supervisors, who were hired into the study (a total of 46 hours). The social workers explained relevant elements of the basis of theories and practices of TCCA to each user, and they discussed how this knowledge could be used to cope with forthcoming challenges. To help strengthen the service users' housing competence, the household guidance was adjusted to every partnership (of users and practitioners) in order to make the goals, agreements, tasks and evaluations as meaningful as possible to the users (Eriksen, 2011a).

An aim of the study was to shed some light on factors that could help strengthen service users' housing competence and everyday life with TCCA. An assumption was that a systematic focus on user participation and practice-based coping knowledge would contribute in making the service users' personal and environmental resources more visible to them. 
The research questions of this article were:

1. How did the service users experience their housing competence and everyday life situation when terminating their collaboration with the practitioners?

2. How did the service users experience the inclusion of TCCA in their efforts to strengthen their housing competence and everyday life situations?

The analysis in this article is organized through these two questions.

In this study, the task-centred approach (TCA) (Epstein \& Brown, 2002; Marsh \& Doel, 2005; Rooney, 2009) was further developed into the task-centred coping approach (TCCA), which will be presented below. TCCA was directed primarily towards not only how the service users experienced challenges in their homes, but also in their everyday life. With a holistic perspective, there may be a mutual interdependence between challenges concerning the home as well as everyday life. Persons with many challenges need the practitioners to holistically deal with their level of housing competence and everyday life in its entirety (Hansen, 2006). Coping with housing challenges implies practical, social and cultural competences. Systematic household guidance involves individually adjusted assistance that increases the chances that users are better able to cope with their housing situations.

\section{The context of household challenges}

Generally speaking, a homeless person is impoverished and often lacks the social skills or emotional stability needed to improve the situation unless help is provided (Barker, 2004). These can vary according to the living situations of the individuals and over the course of time. The term "supported housing", which has been used since the mid-1980s, describes approaches that combine housing assistance and individualized supportive services. This implies both providing access to permanent housing and to services from community-based support providers. Supported housing models were developed when the general failure to focus on housing and support were acknowledged to contribute to unnecessary institutional care for up to one-third of all people in institutions (Ridgway, 2008). Now that fewer institutional beds exist, a central challenge is to take proper care of people who need care and housing of their own, instead of being put into prison or becoming homeless. 
The choice of special category housing as an intervention model seems to perpetuate rather than prevent social exclusion, and can possibly be described as an expression of "institutionalized resignation" (Blid \& Gerdner, 2006). Schiff and Schneider (2010) document that housing practices and models of community care assume homogeneity as the prime criteria for housing type among vulnerable people. However, the living situations of homeless people are diverse, as is their need for housing. In order to achieve stability, build up confidence in relations with practitioners and pursue desires and goals in everyday life, it is critical that housing type is adjusted to individual life situations (Ytrehus, Sandlie, \& Hansen, 2008). It is vital for service users who get their own housing to keep it, which can be challenging if personal and/or environmental resources are scarce. Housing competence means one has personal resources such as the knowledge and skills to cope with and maintain a home. This includes cleanliness, financial planning, taking care of personal hygiene, managing any gardening needs, and having social relationships with visitors and neighbours (Rambøll, 2012). These can be experienced as helpful in assessing the level of competence and individual needs. Collaboration on housing challenges with the TCCA implies strengthening personal experienced shortcomings in some of the areas of housing competence or parts of wider problems in everyday life (Boehnke, 2008; Gallie, Paugam, \& Jacobs, 2003).

\section{From Task-Centred Approach (TCA) to Task-Centred Coping Approach (TCCA)}

The task-centred approach (TCA) provides a basis for the intervention of the programme of the study. It is a short-term approach that has been developed in a number of fields of practice around the world (Epstein \& Brown, 2002; Marsh \& Doel, 2005; Rooney, 2009). TCA is goal-oriented and time-limited, and it is well documented that a time limitation mobilizes the energy of service users. The determination of the goals set forth by the users is an ongoing process during the period of cooperation (Eriksen, 2003; Fortune, McCallion, \& Briar-Lawson, 2010), and the approach is structured into five phases: 1) starting up, 2) problem and resources identification, 3) contracting, 4) implementation and 5) evaluation/ termination. None of the phases are to be omitted, but the collaborators can move backward and forward between the phases as the processes of the cooperation proceeds. The usage of time in the different phases varies between the service 
users, but periods lasting for about three months are recommended. If there is a reason for a longer term, the work can then proceed via a series of shorter term agreements. The work is based on a partnership that is mutually binding, and tasks are carried out to reach goals agreed upon by the collaborators. A task implementation sequence strengthens the probability that the users experience the tasks as meaningful (Epstein et al., 2002). Tasks can be reflection tasks (such as reflections over what alternative coping strategies are possible to reach a specific goal and what consequences the different strategies may have) and action tasks (such as carrying out the chosen coping strategy in practice).

Central theories of TCA are system theory (Andreae, 1996), social learning theory (Bandura, 1997), cognitive theory (Berge \& Repål, 2010), ego psychology (Goldstein, 1995) and communication theory (Miller \& Rollnick, 2013). However, TCA has an eclectic basis of theories, meaning that the actual challenges of service users adjust which theories are the most relevant to enlighten their life situations. Everyday household challenges can be complex, and it can be advantageous to approach them from various theoretical angles. In this study, the theoretical basis of TCA was supplemented with coping knowledge (Eriksen, 2007; 2011a,b; Saleebey, 2013), which led to the task-centred coping approach (TCCA). Coping mechanisms are the behavioural and way of thinking patterns used to adjust or adapt to environmental pressures without altering goals or purposes. Coping skills are a behaviour that an individual uses in responding to or avoiding sources of stress, e.g. obtaining needed information, (pre)planning, maintaining control over one's emotions and impulses, delaying gratification and seeing more appropriate alternative ways to achieve goals (Barker, 2004).

The main purpose of the task-centred coping approach (TCCA) is to increase the self-efficacy of the service users by focusing on the experienced coping of their everyday challenges. Self-efficacy is a service user's belief in his/her ability to accomplish specified tasks that are needed to achieve goals. The practitioner seeks to enhance the user's belief by offering direct assistance, pointing out user strengths, breaking down tasks into doable elements and using all available resources (Barker, 2004). Belief in the possibility of positive change is strengthened the more one 
participates in or copes with various situations (Folkman \& Moskowitz, 2004). This in turn reinforces self-efficacy, which may increase people's coping and participation in various aspects of their everyday life - both as citizens and as service users (Eriksen, 2013). In all stages and aspects of the work, participation is essential. Personal participation is when a service user participates with informal network relations (family, friends and neighbours) and experiences real influence on decisions made in his/her everyday life. While user participation implies that a service user participates with formal network relations (professionals from welfare services), and has real influence on the decisions made in their collaboration, the social workers encourage the service users to be participatory partners in the decision-making process as far as outlining the goals to be achieved, in working out the agreements, in planning and carrying out the tasks and in evaluating the work. The users have expert knowledge about their everyday life, and underlying this approach is an emphasis on the assumption that they themselves know which challenges are most important to address and what potential in the personal and environmental resources (informal social support) is available to cope with these challenges (Eriksen, 2011a,b).

\section{Coping theories as a basis for TCCA}

Antonovsky's coping theories (2000) are a central part of the basis of theories especially his concept of Sense of Coherence (SOC), with a weak or a strong SOC crucial in determining one's ability to cope. SOC has three elements, which consist of an individual's: 1) understanding of the situation, 2) belief in potent solutions and 3) means of carrying them through. Lazarus and Folkman's transactional model (1984:53) has also provided valuable coping knowledge. They characterized various individual cognitive appraisals of experienced stressors, and in their evaluation of stressors, environmental factors and the individual were emphasized, as well as the integration of factors from both parts of a given transaction. A transaction was defined as the creation of a new level of abstraction, and factors from both the individual and the environment were integrated to create a new relational meaning in the current context (Lazarus et al., 1984:294). The researchers emphasized personal coping (intrapersonal processes) and interactional coping between the individual and the environment (interpersonal processes). Literature regarding coping demonstrates a broad application of the coping concept (Folkman \& Moskowitz, 2004; Ekeland \& 
Heggen, 2007:64-82), and in this study, coping in TCCA is understood as movements toward a desired outcome. Movements are conscious thinking and actions. Some examples of personal coping resources are knowledge, motivation, confidence, responsibility and competence. The environment consists of persons in the individual's informal or formal networks, and might be experienced as resources or as challenges. Social support revolves around environmental coping resources provided by others such as respect, confirmation of meaning, direct assistance (e.g. material things, practical assistance, information) and interdependence in a group (Eriksen, 2007). To be able to cope, citizens must participate in their everyday life, as coping and participation seem to be mutually dependent. Practitioners are advised to build upon the participation and coping that service users have established in their everyday life as citizens, as well as individuals using services (Eriksen, 2013). User participation implies informed service users who enforce their influence on the decisions taken with their professionals.

\section{Research method}

The design was based on a way of participatory action research (PAR), in which the researcher was positioned as a partly participating researcher. On the one hand, the researcher attempted to attain knowledge from the individualized activities of the service users and social workers, while on the other hand using this knowledge as a contribution to developing their practice (Sverdrup, 2013). The role of the researcher was divided into: 1) developing the programme, and 2) developing the practice of the participants. The concept of a partly participating researcher is used in this article since the role of the researcher is more limited here. This article focuses on the second part of the researcher's role, namely the results for the participants from the service users' perspectives. Individualized activities mean matching programme services and treatments to the need of individual service users, with flexibility, adaptability and individualization being important to the effectiveness of educational and human services programmes (Patton, 2002:154).

The implementation of the programme was based on an empowerment evaluation with the intention of engaging the participants by giving them influence and "a voice". The goal was to promote participation and developmental processes by 
systematically asking for their experiences and coping resources. According to Fetterman (2001), empowerment evaluation would strengthen their capacities to participate in the processes of knowledge production and to contribute with their personal expertise from their positions. The partly participating researcher gave lecturers at the programme's gatherings, commented on the service users and the students/practitioners presentations and took part in occurring discussions. Half of the lectures were given by external, hired researchers and practitioners. The researcher had many years of experiences as a social worker and researcher, and may have been seen as an expert by both the service users and practitioners. However, the researcher emphasized that this study was aiming at developing a richer knowledge about how to strengthen service users' housing competence and everyday life with the TCCA. A diversity of knowledge and social contexts of the experiences of the participants were important to obtain.

The study was comprised of 74 service users and 20 practitioners from the MSS in four municipalities. Social workers who volunteered and gained approval by their employers were included in the study. Users who approached the MSS agencies during the period of recruitment were invited to participate, and informed consent was emphasized. All prospective participants received information regarding the study, which was a way to utilize self-selection and convenience sampling on an availability and willingness to participate (Padgett, 1998). Informants were recruited in accordance with the capacity of time of the practitioners. The eligibility criteria for participation in the study were service users (ranging in age from 18 to 62 years) who had housing of their own and experienced housing challenges, were unemployed and supported by allowances, and who had an addiction and/or mental health problems. The study was approved by the National Social Science Data Services (NSD).

This article is primarily based on forms of retrospective self-evaluation, which service users filled out after their collaboration with the TCCA. They delivered 62 forms: 35 were filled out in the informants' homes, 27 in the practitioners' offices and 12 dropped out $(\mathrm{N}=62)$. The reasons for the drop-outs were reported to be that the informants were in vulnerable living conditions (e.g. bad health, comprehensive 
addiction, life crisis) or the collaboration had not ended. The form consisted of 10 open questions divided into two groups of five questions concerning the informants' experienced processes of development of: a) their life situations and b) their collaboration with the TCCA with their social workers. Examples of questions were:

Group a): How did you experience your everyday life and housing challenges when you entered this study? How do you experience your everyday life and housing challenges today?

Group b): How did you and your social worker collaborate when using the TCCA? What experiences promoted your collaboration? What experiences obstructed your collaboration?

After each question, the informants were asked to give descriptive examples, and the details and richness of the informants' narrative answers varied.

The analytical processes were initially characterized by reading and rereading the messages to achieve an in-depth familiarity with the text in the forms. On the basis of a phenomenological perspective, the researcher was interested in getting knowledge of the subjective experiences of the informants' everyday life: What was the meaning, structure or essence of their experiences? What challenges did they experience? What factors relieved their situations? How did they experience to better cope with their challenges individually, as well as with their environment? Did they experience a weaker or stronger SOC? Similarities and differences were searched for in the single form and across all the forms. Condensation of meaning was used to reduce the volume of the text without reducing its variations of meaning. This description adhered closely to the original text, and the next step was transforming the text in a way that highlighted the implicit experiences of meaning. In these processes, themes emerged such as an increased consciousness and diversity in self-understanding, resource orientation, user participation - feeling of ownership, time as a limited resource and the TCCA - a tool to create realism and an overview. Analytical questions to the text led to analytical categories and condensed narratives as illustrations of their messages (Patton, 2002). By posing these analytical questions, the researcher has managed to a certain extent to attend to the data's richness and 
variations, while at the same time developing knowledge to understand how the informants have experienced their life situations and the TCCA. An extract of these narratives is presented in the results.

The service users' retrospective self-evaluation forms were collected by the practitioners without any influence from the researcher, and the informants' assessments emerge from their evaluation. However, the researcher has chosen quotations from the informants, and consecutively made her evaluations and interpretations of them. The data were translated from Norwegian into English.

\section{Results}

1. How did the service users experience their housing competence and everyday life situation when terminating their collaboration with the practitioners?

In general, the users expressed that they were satisfied with the service they had received with their practitioners aimed at strengthening their coping with housing and everyday challenges. They mentioned positive changes such as: an increased control of their life situations, an improved standard of living, an increase in consciousness about their ways of thinking, a greater ability to structure their everyday life, increased positive feelings, new or safer housing, a reduction or termination of addiction and/or mental problems, increased leisure activities or social interactions, employment, receiving education or better financial stability. Several were waiting for their applications to be handled, but felt that they had actively made efforts to better cope with their challenges. If they wanted to, they engaged in a new TCCA period with other goals. Such inquiries might support service users' coping and was a part of practicing user participation, and were met by improvised contacts (e.g. e-mails, telephones) or fixed appointments. Some of the most vulnerable service users participated little in systematic household guidance at the time of the data collection, which was due to more difficult periods in their everyday life such as increased addiction and/or mental problems, and some were hospitalized for days or months. However, they kept their housing and the relationship with their practitioners in the MSS while they were away. According to Ytrehus et al. (2008) and Tsemberis 
(2010), permanent housing of your own and confidence in relations with helping practitioners are among the central contributors in stabilizing life situations.

The narrative below illustrates how a depressed woman was motivated to take action. User participation seems to have been of great importance to her. As she began her processes of making changes, she gained energy:

I needed to learn how I could receive help. She let me make the decisions about what was going to happen. Decisions can be difficult to make, but once you have made them you have to comply with them. We made some goals and tasks. She gave me hints and made me reflect in different ways. She pushed me to get hold of a new apartment, established my professional support group, and I started to take my medication regularly. I don't need more help now.

This informant emphasized how important participation was for her. She wanted to make crucial decisions concerning her life situation, and the practitioner made her reflect in new ways. Increased consciousness made her discover new possibilities about how to cope with her challenges. She still missed friends and was afraid of leaving her house, but she experienced that her life was moving in the "right" direction.

This quotation illustrates how increased self-reflections and consciousness could lead to meaningful experiences such as joy and social participation:

I feel more at peace. When you're starting to change yourself, you have to really discover it - what it is that you manage better. I had to do things in my own way. I have learned to put things into words ---name them to myself. There's joy in my house now, because l've become more social. Managing things makes me happy. It gives me a feeling of hope for the future.

Their narratives illustrate how different factors can be mutually dependent upon one another. Increased trust in themselves could lead to more increased well-being, more 
energy and less loneliness and vice versa. This study was based on the informants' conscious coping, and the data indicated that the informants had gained advantages from the processes of becoming more conscious of how they experienced their housing competence, their coping with everyday life and the changes they actually wanted to make. Berge et al. document that positively experienced coping processes are often intertwined and seem to reinforce each other (Berge et al., 2010). It seems important that practitioners had refined skills, which helped the service users to systematically reflect on and strengthen their coping capacities and environmental social support. Even so, the informants had to experience an influence on decisions made in regard to what changes, and how and when the changes, would be put into action. This could indicate that achieved coping and goals imply hope for their future.

The following two quotations illustrate how service users worked with themselves, as well as with persons in the environment:

People can be stuck in one track, but this was easier than I thought. I found great advantage in having decided to stop taking more drugs. If I hadn't stopped, I doubt I could have managed to keep our appointments. Our work was important to me. I ended a negative relationship with a drug friend. I'm more optimistic in trying to stretch my limits. I do things that I didn't do before. Our cooperation has implied a deeper relationship which increased my trust in her. It was helpful to reflect on my network. My neighbour inspires me to do "the right thing"!

Another informant expressed:

You have to stop seeing yourself as an addict, and other people have to stop doing that. When you use drugs, you are in a bubble and do not notice people around you. Addicts believe other people are normal and live in a normal society. They think that they have burned all bridges to them. That's wrong. Now I've become one of the normal others. I didn't have any contact with my family. I got help from my girlfriend and my worker to see what to do when I decided to quit using drugs. I was surprised to see how quickly I gained my 
family's confidence. They took me into their warmth again, which meant a lot to me when trying to stay clean. I did not need my practitioner as much as before. My "drug friends" tried to deceive me by making good offers: "You can have this for free!" I had to learn to say "no".

The cooperation with the TCCA may lead to an increase in awareness regarding social networks and possibilities for social support (e.g. family, neighbors and practitioners). The service users had only given slight consideration to the people who could promote or hinder their coping processes. When their networks were analysed together with their social workers, resources were uncovered that could be used in assisting their efforts of coping and strengthening their housing competence. In the processes of learning more about themselves and what they wanted to be, the self-efficacy of users could change. From experiencing themselves as "an addict" outside society, they gradually looked upon themselves as "a normal other" inside the society. They emphasized the importance of terminating relations to friends with drug addiction challenges. Fyrand also documents this need and argues that to decrease feelings of loneliness, some of these terminated relationships have to be replaced with new or former persons who are not involved with drugs. Social support is vital, particularly in periods of high vulnerability (Fyrand, 2005).

2. How did the service users experience the inclusion of the TCCA in their efforts to strengthen their housing competence and everyday life situations?

Generally speaking, it seems to be crucial to practice the TCCA adjusted to the actual life situation of each service user. The users knew what kind of household guidance they could take advantage of to improve their housing challenges, and they expressed that experienced motivation was important to get started. Motivation is a continuing process and it varies as time passes by, but is particularly important when the working relationship is being established (Miller et al., 2013).

The following narrative illustrates that this service user had to understand what the TCCA was, and that successful experiences were motivating: 
We met on a weekly basis. I had to pull myself together and decided to change myself. Much is being filtered without thinking of it - both resources and the network. It's ok to put things on a sheet of paper. You then see someone cares about you, what things you manage and what you have done. My days and finances are more structured now. I just had to have small goals since I was an impatient lad and wanted things to happen. I liked action tasks. A little victory at the time made a nice impression. I'm on my way to reaching my goals.

The practitioners had to be sensitive to the needs of the service users. Some of the users expressed appreciation for being pressured, while others emphasized the patience and empathy of the professionals. By dividing the main goal of the service users into smaller goals, it seemed to be easier to cope. Their motivation was strengthened by experiencing that goals which they had agreed upon were possible to reach.

The quotation below illustrates how changes in the ways of thinking by reflection tasks made the service user discover more possibilities:

I learned a lot from my reflection tasks. They made me see things from different angles. I had to move at my own pace. Then my choices were more clearly founded. I thought of different stuff that was difficult and I managed to find better solutions than before. I'm socially more active now because of a girlfriend. My flat is nice both inside and outside due to some practical tasks. I dare to sit outside and talk with my neighbours. I want to have a more meaningful everyday life - like taking a course? I may contact my practitioner again if things are getting worse. Maybe I'll just phone her or maybe we'll meet and work together for some time again. She has shown me confidence and believed in me - she was strict in a positive way!"

In regard to analysing the challenges and resources of service users' housing competence and everyday life, reflection tasks can be useful tools. What alternatives were available and what consequences may they imply? In the transference between 
reflection tasks and action tasks, user participation can be decisive. This practitioner seemed to have reduced her own influence by letting the user decide when it was the right time to move from reflection tasks to action tasks. Their relationship was terminated, and the service user decided if new contact was necessary. The way this user understood himself was strengthened by someone who showed him confidence. "To be strict in a positive way" may deal with balancing between making demands for greater effort, while giving motivating emotional support.

When the cooperation was terminated, this service user did not know whether he and his practitioner would start a new TCCA period. Based upon his experiences, he knew that his practitioner was there for him if he was in need. Several users stressed that the TCCA had to be used in flexible manners, and adjusted to actual persons and situations. Some of them needed more time in different phases of their work than others. This flexibility has to be in accordance with principles based upon research, including an important principle that a planned and limited use of time mobilizes the energy of the service users. However, this principle does not overrule the user's individual needs. Reflection tasks are generally advised to be carried out first to stimulate the processes of forming the most meaningful action tasks of the service users. Some decisions need to ripen before considering the best alternative to be carried out (Berge et al., 2010), while in other situations action tasks have to be carried out rather quickly because it is obvious what action tasks must be done such as paying bills that are due.

\section{Discussion}

\section{Increased consciousness and diversity in self-understanding}

Some service users expressed that they had learned to understand themselves and their environment with more diversity. Their skills in undertaking cognitive appraisals of experienced stressors and resources seem to have been strengthened. Analytical reflections, together with their practitioners, might have uncovered possible resources. Experiences of SOC may have increased their coping skills. The TCCA sessions seemed to influence the thinking of the users, which made them better understand how they could put their wants into actions. The service users described how their consciousness became more positive, as they seem to have become more 
aware of how they thought about themselves, which implied that they discovered new possibilities. Previously, they experienced other people as more capable and resourceful than themselves, and some experienced a change in their selfknowledge from being "an addict outside society" to becoming "a normal other inside society". Gradually, the attention for some of them might have been turned towards their own development, what they wanted and that they might be able to cope in different ways.

Some users seemed to appreciate investing time in working with cognitive appraisals through the TCCA. These reflections may have contributed in making their goals clearer to them, whereas others stressed the importance of "things to happen" in their lives. They seem to have preferred action tasks rather than reflection tasks, though their preferences might depend on their evaluations of the most important challenges in their everyday life.

\section{Resource orientation}

Researchers have documented that service users of MSS have deficient housing and living conditions (van der Wel et al., 2006). Despite their often difficult living conditions, the users had a lot of personal and environmental resources. When they became more conscious of their resources and experienced a decline in their challenges, their experiences of coping seemed to increase. Their coping seemed to strengthen their self-respect and hope for the future, which released energy for new efforts.

An ongoing dilemma in TCCA sessions is balancing between the right timing of either focusing on resources or challenges. Where is the boundary in which the service user experiences too much anxiety, which may imply defeat in not coping with planned tasks? Where is the experienced boundary for users who suffer from tediousness, which may imply feelings of meaningless cooperation with the practitioners? Coping orientation focuses on the possibilities in the individual and the environment, but at the same time this orientation does not neglect the challenges that often accompany housing and everyday life. Some of the drop-out informants were reported to be in more vulnerable periods than were usual for them. According 
to Saleebey (2013), it is important to pay respect to the pain and sorrow that the users may experience in difficult periods of their lives.

\section{User participation - feeling of ownership}

An aim of the intervention was to strengthen the housing competence and the everyday coping of the service users. When the users felt that they were taken seriously, their coping confidence and motivation were strengthened, and their housing and everyday life were diverse. The contents and goals for their coping processes could differ among the service users, and some were impatient for results. They knew what changes they wanted, and started their efforts to implement them rather quickly. Others were ambivalent and needed more time in the periods of assessment and making decisions. Although the goals of the users may have been desired, the changes they could bring may have resulted in bad feelings and/or difficult consequences. These service users emphasized that they themselves had to decide when they were ready to move from reflection tasks to action tasks, as their decisions had to ripen. They had to feel relatively secure in their planning of action tasks and how, when, and where they were to be carried out. User participation also implied the right to choose no action tasks, because they were experienced as being too troublesome. The right timing for action tasks seemed to be when the users had named what changes they found meaningful and had put this into their own wording (i.e. the code of their culture). This phenomenon seemed to increase their feelings of ownership for the ongoing planning. Several of the service users appeared to be more independent, as if they had increased their influence on their housing competence and everyday life.

\section{Time as a limited resource}

Some service users had a rather complicated everyday life, and short-term approaches seemed challenging to practice. The TCCA can be useful to achieve results, even in long-term work. In the most turbulent periods, hospitalization for shorter periods could be necessary. After the hospitalization, the TCCA cooperation continued in the housing of the users. However, after a planned termination of the cooperation, the service users asked for service in flexible patterns such as simply calling their practitioners to get some housing guidance and support in their coping. 
Others might ask for a new period of cooperation to assess their actual life situations and revise a new agreement. Since the life situations of the service users varied, the use of time in the partnerships had to be adjusted to the single user.

Periods of up to three months are recommended to weaken the probability that the collaborators, e.g. develop a relation of dependence (Marsh et al., 2005). When needed, the short-term TCCA was used with a long-term perspective. Subsequently, the participants might have several periods of the TCCA. Between the periods of the TCCA, the service users worked with tasks and achieved goals without their workers' cooperation. Interval targets were needed along the way to the main target, and larger challenges were broken down into separate parts, with each gain building upon the last. During such periods, the users seemed to experience an increase in their coping confidence and become more independent. When in need of social support, they asked persons in their informal networks for assistance. Social network analysis gave several service users increased consciousness about how they could mobilize social support.

\section{TCCA - a tool to create realism and overview?}

Some service users were not motivated at the outset, and in their most vulnerable periods they had no hopes of a better future. The practitioners put this on their agenda, wavering between positive and negative incentives until the users were motivated for a minor change. If not, they took a pause. They agreed that after some time, either the service user or the social worker paid the other one a visit.

When practicing the TCCA, formulating achievable goals is a continuing process between the service user and the practitioner. Writing down elements like what tasks the users had coped with and carried through created an overview of what was central in the cooperation. Some experienced the writing as visible "evidence" that the practitioner did care for them. When goals were limited in scope, it seemed to be easier to plan and carry through specified tasks to reach them. However, the service users had to feel free in adjusting their goals, as their cognitive appraisals helped them become clearer in what they wanted. For instance, in more vulnerable periods, some users could have difficulties in thinking clearly due to bad health, which implied 
shorter sessions. An evaluation of a single session or of a limited period of time is emphasized as a possible advantage in keeping the overview of the progress. According to Epstein et al. (2002), systematic evaluations may strengthen the quality of the MSS as well as the experienced learning of the participants.

\section{Need for more knowledge}

The study seems promising in accordance with the users' experiences in a relatively short time, and several of them experienced better coping with their housing and everyday life challenges. Whether these tendencies are stable could be checked and compared by interviewing users six and/or twelve months after ending the study. The evaluation could enlighten how the interventions were experienced then. Nevertheless, it is uncertain what influence the TCCA may have had on the achieved findings, and what may be ascribed to other factors, e.g. support from a new girlfriend, or achieving a better housing or economy. Lambert and Bergen (1994) report that factors other than approaches and techniques determine the result of a helping relationship. The user's personal resources, incidents outside the practitioners' office and the user's evaluation of the relationship with his/her practitioner have the most decisive influence. According to Hannan et al. (2005), users' and practitioners' evaluation of how their cooperation function may imply major differences from each other.

However, by using the TCCA, some positive results are achieved. There is reason to believe that the approach has strengthened the experienced housing competence of some users.

The transferability of the results is more uncertain, since the interpretation of a text always involves multiple meanings, and the interpretations of the researcher are influenced by both professional and personal history (Graneheim \& Lundman, 2004). A closeness to the data was required in order to be able to describe and develop the TCCA. To be a part of the research field complicates having a distanced and objective perspective on the ongoing collaboration of the TCCA, as no research is neutral in the sense of being free of values (Patton, 2002; Pirskanen, 2009). The 
researcher strived for consciousness and a focused reduction of her own point of views, being aware of actual dilemmas and challenges in researchers' objectivity.

More research is necessary to acquire a richer knowledge about what is experienced as relevant and useful for the service users in their different housing, and in their everyday life in general. The TCCA could be compared and tried out together with more service users and MSS, either nationally or internationally. The TCA has been implemented and tested in a broad range of settings and with diverse service user groups (Fortune et al., 2010). The TCCA is fully based on the TCA, but the eclectic theory basis of the TCA is further developed to the task centred coping approach (TCCA), which systematically focuses on user participation and coping knowledge.

\section{Conclusions}

The service users of the study generally seemed to be satisfied with the services they had received from their practitioners in the MSS. They mentioned a higher standard of living, a better control and structure of everyday life and improved living conditions such as safer or better housing. An orientation towards coping and user participation seemed to have strengthened their experienced housing competence and knowledge about themselves and their environment. They increased their consciousness of their personal and environmental resources, which gave them more hope for the future.

The TCCA seems to have a potential for strengthening the housing competence and coping in the everyday lives of the service users. In this research, the TCA was adjusted to the TCCA so that the participants systematically focused on the assessment and use of resources and coping experiences. When the users experienced achieving their goals, their thinking and feelings seemed to be more positive, thereby motivating them to proclaim new goals. Their consciousness might have been more centred around the possibilities of discovering or mobilizing personal or environmental resources. Time limitations of the efforts of the practitioners might also have generated energy for the service users. This phenomenon is supported by Epstein (2002), who states that time limitations mobilize the energy of service users. She argues that successful outcomes of short-term approaches are the result of the 
structured effort induced by time limits. The TCCA has a structure of five phases. Short-term approaches tend to be focused and active, which help the collaborators to better understand where they are heading. Still, the collaboration was not always short term, as interval targets were needed along the way to the main target. The use of social network analysis gave the service users opportunities to understand themselves in different contexts. Such an analysis led to an increase in awareness in the persons who could contribute with social support and those who could not. This systematic work of reflections contributed in making coping agreements between the service users, their social networks and their practitioners.

The study can be interpreted as providing arguments against a too rigid standardization of professional approaches that support user participation and adjustment to individual service users and his/her actual social context. It is challenging to be both flexible and empathetic to the service users' individual needs, while at the same time focusing on the planned goal of the TCCA. The challenges of the users varied from person to person, and their life situations changed as time elapsed. Some experienced more turbulent swings than others, individual adjustments were vital and the service users' life situations were often turbulent. Planning, which takes such ongoing variations into account, also seems to be important. Continuity in the cooperation with the TCCA can be more challenging for the service users in periods with heavier burdens in their everyday lives. In vulnerable periods, the focus has to be concentrated on social support and keeping up achieved goals, as expectations of new coping-oriented changes seem to be less appropriate. 


\section{References}

Andreae, D. (1996). "Systems theory and social work treatment". Social work treatment. In F. Turner (Ed.), New York: Free Press. 581-600.

Antonovsky, A. (2000). The mystery of health. Copenhagen: H. Reitzels Forlag.

Bandura, A. (1997). Self-efficacy: the exercise of control. New York: Freeman.

Barker, R. (2004). The social work dictionary. Washington: NASW.

Bengtsson, S., Jørgensen, H., \& Grønfeldt, S. (2013). Social services to people with mental illnesses. [Sociale tilbud til mennesker med sindslidelser.] 32. Copenhagen: National Research Center of Welfare.

Berge, T., \& Repål, A. (2010). The inner conversation. [Den indre samtalen.] Oslo: Gyldendal.

Blid, M., \& Gerdner, A. (2006). Socially excluding housing support to homeless substance misusers. International Journal of Social Welfare. 15:162-171.

Boehnke, P. (2008). Are the poor socially integrated? The link between poverty and social support in different welfare regimes. Journal of European Social Policy. 18:133-150.

Ekeland, T.-J., \& Heggen, K. (2007) Coping and empowerment. [Meistring og myndiggjering.] Oslo: Gyldendal.

Epstein, L., \& Brown, L. (2002). Brief treatment and a new look at the task-centered approach. Boston: Pearson.

Eriksen, R. E. (2007). Everyday life of long-term service users: Coping in a (user)participation perspective. [Hverdagen som langtids sosialklient: mestring I et (bruker-)medvirkingsperspektiv.] Dr.thesis, Trondheim: NTNU. 
Eriksen, R. E. (2011a). Social work with persons who want to improve their housing competence. [Sosialt arbeid med personer som trenger booppfølging.] 8. Oslo: The Directorate of Employment and Welfare and Diaconia University College.

Eriksen, R. E. ( 2011b). The coping model: What is it and what might be its implications for social work practice? European Journal of Social Work. 1:1-17.

Eriksen, R. E. (2013) Participation and coping: A mutual dependence? Social Work and Social Sciences Review. 17(1):22-34. DOI: 10.1921/1103160301.

Fetterman, D. M. (2001). Foundations of empowerment evaluation. Thousand Oaks: Sage.

Folkman, S., \& Moskowitz, J. (2004) Coping: Pitfalls and promises, Annual Review of Psychology. 55:745-774.

Fortune, A., McCallion, P., \& Briar-Lawson, K. (2010). Social work practice research for the $21^{\text {st }}$ century. New York: Columbia.

Fyrand, L. (2005). Social networks. [Sosiale nettverk.] Oslo: Universitetsforlaget.

Gallie, D., Paugam, S., \& Jacobs, S. (2003). Unemployment, poverty and social isolation. Is there a vicious circle of social exclusion? European Societies. 1:1-32.

Goldstein, E. (1995). Ego psychology and social work practice. New York: Free Press.

Graneheim, U., \& Lundman, B. (2004). Qualitative content analysis in nursing research. Nurse Education Today. 24:105-112. 
Hansen, I. L. S. (2006). Need for housing and welfare services of persons with mental illnesses. [Bo- og tjenestebehov hos personer med psykiske lidelser.] 519. Oslo: Fafo.

Hannan, C., Lambert, M., Harmon, C., Nielsen, S., Smart, D., Shimokawa, K., \& Sutton S. (2005). A lab test and algorithms for identifying clients at risk for treatment failure. Journal of Clinical Psychology. 61:155-163.

Lazarus, R. (1999). Stress and emotion. New York: Springer.

Lazarus, R., \& Folkman, S. (1984). Stress, appraisal and coping. New York: Springer.

Marsh, P., \& Doel, M. (2005). The task-centered book. London: Routledge.

Miller, W., \& Rollnick, S. (2013). Motivational interviewing. New York: Guildford.

Padgett, D. (1998). Qualitative methods in social work research. Thousand Oaks: Sage.

Payne, M. (2005). Modern social work theory. Hampshire: Palgrave.

Pirskanen, H. (2009). “Was your father a problem drinker?” Journal of Comparative Social Work. 1:1-17.

Patton, M. (2002). Qualitative research and evaluation methods. Thousand Oaks: Sage.

Pettersen, H., Ruud, T., Ravndal, E., \& Landheim, A. (2013). Walking the fine line: Self-reported reasons for substance use in persons with severe mental illness. International Journal of Qualitative Studies on Health and Well-Being. 8:doi:10.3402/qhw.v8i0.21968. 
Rambøll (2012). Housing first - possibilities and obstructions for implementation in Norway. [Housing first - muligheter og hindringer for implementering I Norge.] Oslo: Husbanken.

Ridgway, P. (2008). "Supported housing". Clinical handbook of schizophrenia. In Mueser, K., \& Jeste, D. (Eds.), London: Guildford. 287-297.

Rooney, R. (2009). Strategies for work with involuntary clients. New York: Columbia.

Sahlin, I. (1996). På gränsen till bostad. Avvisning, utvisning, specialkontrakt. [On the border of housing.] Lund: Arkiv förlag.

Saleebey, D. (2013). The strength perspective in social work practice. Boston: Pearson.

Schiff, R., \& Schneider, B. (2010). Housing for the disabled mentally ill. Canadian Journal of Urban Research. 19(2):108-128.

Sullivan, G., Burnam, A., \& Koegel, P. (2000). Pathways to homelessness among mentally ill. Social Psychiatry. 35:444-450.

Sverdrup, S. (2013). "Participatory action research as a newer tendency in Norwegian evaluation". Evaluation. In Halvorsen, A., Madsen, E., \& Jentoft, N. (Eds.), Bergen: Fagbokforlaget. 134-147.

The Directorate of Health and Social Affairs (2005). National strategy for improvement of quality of health- and social services 2005 - 2015. [Nasjonal strategi for kvalitetsforbedring av helse og sosiale tjenester.] IS-1162.

The National Board of Health Supervision (2008). Report of supervision 2007, Supervision of the health and social services. [Tilsynsmelding 2007].

Tsemberis, S. (2010). Housing First. Center City: Hazelden. 
Underlid, K. (2005). The psychology of poverty. [Fattigdommens psykologi.] Oslo: Norske samlaget.

Wel, K. van der, Dahl, E., Løyland, B., Slagsvold, M., \& Lødemel, I. (2006).

Functional abilities among users of welfare services. [Funksjonsevne blant langtidsmottakere av sosialhjelp.] Oslo: Oslo University College.

Ytrehus, S., Sandlie, H. C., \& Hansen, I. L. S. (2008). In the right direction. [I riktig retning.] 8. Oslo: Fafo. 